\title{
Mesenchymal stem cell therapy for osteoarthritis: current perspectives
}

This article was published in the following Dove Press journal:

Stem Cells and Cloning: Advances and Applications

28 August 2015

Number of times this article has been viewed

\section{Cody CWyles' \\ Matthew T Houdek ${ }^{2}$ \\ Atta Behfar ${ }^{3}$ \\ Rafael J Sierra ${ }^{2}$}

'Mayo Medical School, ${ }^{2}$ Department of Orthopedic Surgery, ${ }^{3}$ Division of Cardiovascular Diseases, Mayo Clinic, Rochester, MN, USA
Correspondence: Rafael J Sierra

Department of Orthopedic Surgery,

Mayo Clinic, 200 First Street SW,

Rochester, MN 55905, USA

Tel + I 50728425 I I

Fax +I 5072848935

Email sierra.rafael@mayo.edu
Abstract: Osteoarthritis (OA) is a painful chronic condition with a significant impact on quality of life. The societal burden imposed by OA is increasing in parallel with the aging population; however, no therapies have demonstrated efficacy in preventing the progression of this degenerative joint disease. Current mainstays of therapy include activity modification, conservative pain management strategies, weight loss, and if necessary, replacement of the affected joint. Mesenchymal stem cells (MSCs) are a multipotent endogenous population of progenitors capable of differentiation to musculoskeletal tissues. MSCs have a well-documented immunomodulatory role, managing the inflammatory response primarily through paracrine signaling. Given these properties, MSCs have been proposed as a potential regenerative cell therapy source for patients with OA. Research efforts are focused on determining the ideal source for derivation, as MSCs are native to several tissues. Furthermore, optimizing the mode of delivery remains a challenge both for appropriate localization of MSCs and for directed guidance toward stemming the local inflammatory process and initiating a regenerative response. Scaffolds and matrices with growth factor adjuvants may prove critical in this effort. The purpose of this review is to summarize the current state of MSC-based therapeutics for OA and discuss potential barriers that must be overcome for successful implementation of cell-based therapy as a routine treatment strategy in orthopedics.

Keywords: mesenchymal stem cell, osteoarthritis, treatment, regenerative medicine, cell therapy

\section{Introduction}

Among the various forms of degenerative joint disease, osteoarthritis (OA) is by far the most common and represents a painful chronic condition that can affect any synovial joint. ${ }^{1}$ Disease prevalence is increasing in parallel with an aging population and will impose significant socioeconomic burden over the coming decades. ${ }^{2-4}$ Arthritis is the most common source of disability among adults in the United States; in 2003, the disease afflicted 50 million Americans and this number is expected to increase to 67 million by 2030.5,6 The cost attributable to arthritis in the United States in 2003 was $\$ 128$ billion, a figure that will certainly increase in conjunction with health care cost inflation and the number of patients projected to be afflicted with degenerative joint disease. ${ }^{6}$ Complicating this reality are the limited treatment options for OA. No pharmaceutical or non-operative therapies have demonstrated unequivocal efficacy in reversing or halting disease progression, restricting therapy to long-term management of exacerbating factors and pain control. ${ }^{7}$ Surgical options such as osteotomies exist for improving alignment and decreasing risk of OA when mechanical deformity 
is present; however, these procedures have limited benefit once significant degenerative changes have taken place. ${ }^{8}$ Surgical intervention can also be pursued for focal articular cartilage lesions with techniques such as microfracture, osteochondral grafts, or chondrocyte implantation that may be accompanied by scaffolds or matrices. ${ }^{9-15}$ Despite advances in these procedures, they cannot be applied to more extensive damage in the joint secondary to OA. In the absence of effective strategies, the search for diseasemodifying treatments continues.

Mesenchymal stem cells (MSCs) have been proposed as an optimal regenerative cellular therapeutic for degenerative musculoskeletal conditions like OA. ${ }^{16}$ These cells are found in a variety of tissues and have the ability to rapidly proliferate and differentiate to musculoskeletal lineages including bone and cartilage. ${ }^{17} \mathrm{~A}$ significant body of research has also demonstrated that these cells orchestrate important immunologic functions through modulation of the local inflammatory response. ${ }^{18}$ Taken together, these factors support the theoretical ability of MSCs to deter degenerative joint disease. Research efforts have focused on defining the ideal source for MSC derivation, as this cytotype exists in a broad array of tissues. ${ }^{19}$ Optimizing appropriate localization of MSCs in tandem with the use of scaffolds and matrices to maximize regenerative potency and local immunomodulatory impact are critical challenges in this effort.

The purpose of this review is to summarize the current state-of-the-art in MSC-based therapeutic efforts to treat OA with a look ahead toward obstacles impeding successful implementation as a routine treatment strategy.

\section{Current treatment approach to patients with OA - an unmet need}

Treating patients with OA presents a significant challenge for physicians as no therapies to date have demonstrated efficacy in curing or even halting disease progression. Therefore, most approaches initially target pain management and factors that may be exacerbating stress on the joint. Conservatively, this involves weight loss, modifying painful activities, initiating a program of low-impact exercise and stretching, the use of braces or gait aids, and over the counter analgesic medications or creams. ${ }^{7}$ Modalities from alternative and complementary medicine are often pursued by many patients as well. ${ }^{20}$

When these first-line strategies fail, a trial of corticosteroid injections may be pursued. Current guidelines suggest a maximum of four injections per joint per year. ${ }^{21}$ Efficacy of these agents is highly variable between patients and the period of relief afforded by corticosteroids tends to shorten with each subsequent administration. ${ }^{22}$ Furthermore, injected corticosteroids have known toxicity to both chondrocytes and MSCs, thus potentiating OA progression in exchange for temporary pain relief. ${ }^{23-25}$ However, the degree of toxicity differs with respect to the specific formulation. ${ }^{25}$ Elective surgery on the joint receiving a corticosteroid injection is recommended to be delayed at least $8-12$ weeks as wound healing is temporarily impaired. ${ }^{21}$ If corticosteroid injections fail to provide relief, then injectable hyaluronic acid preparations may be pursued, although there is conflicting evidence as to patient improvements with regard to pain or function. ${ }^{26}$

The ultimate solution for OA refractory to all other modalities is total joint replacement with artificial prosthetics. These procedures are most commonly and successfully applied to the hip, knee, and shoulder joints; however, options are expanding in many other joints including the elbow, ankle, and at multiple locations in the hand. ${ }^{27-29}$ Total joint replacement represents some of the most successful procedures ever devised in modern medicine. Despite these advances, complications still exist, prosthetic joints cannot match the functionality of a native joint, and access to these procedures falls well short of demand. ${ }^{3,4}$ Clearly, there is a substantial unmet need for this chronic disease that would benefit greatly from disease-modifying therapy.

\section{MSC tissue sources, physiology, and function}

MSCs have been proposed by many as an optimal regenerative cellular therapeutic for musculoskeletal regeneration, especially in the setting of degenerative pathology like OA. ${ }^{30,31}$ Defining characteristics include the ability to rapidly proliferate and differentiate to tissues of mesenchymal lineage including bone, cartilage, and adipose in conjunction with the presence of typical surface markers. ${ }^{17}$ The proliferative capacity, differentiation potential, and surface marker profile differ based on the tissue of origin. ${ }^{17-19,32-37}$ MSCs have been isolated from a variety of tissues, with primary interest for treating $\mathrm{OA}$ being generated from either the bone marrow or adipose tissue (Figure 1). ${ }^{16,37-39}$

MSCs seem to provide critical advantages over chondrocytes when considering treatment of degenerative conditions like OA. First, they are much easier to culture and expand ex vivo. ${ }^{17}$ Proliferation is more rapid and they maintain their phenotype to a greater degree during this process. Furthermore, chondrocytes are terminally differentiated, whereas MSCs can specialize to all tissues within the joint. Theoretically, this enables them to repair lesions restricted 


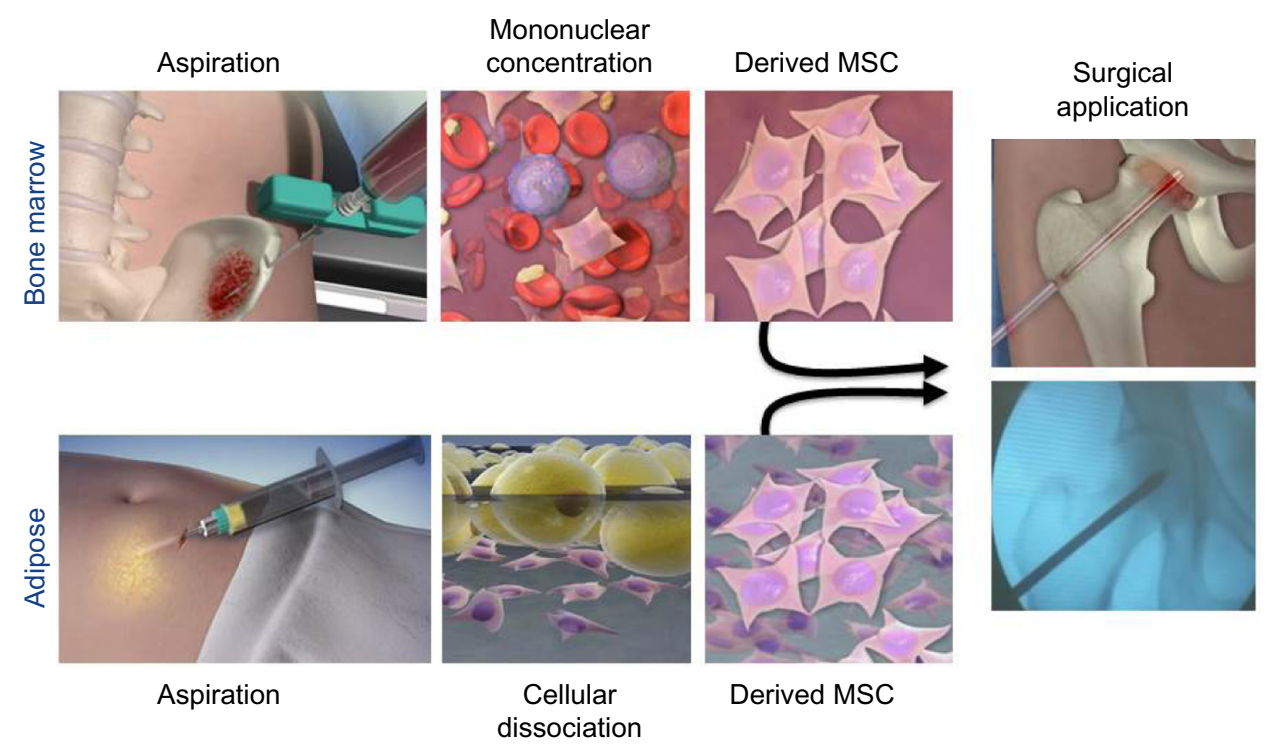

Figure I Techniques for derivation and surgical application of bone marrow- and adipose-derived MSCs. Following extraction of either bone marrow (top row) or adipose tissue (bottom row), MSCs can be isolated and subsequently transplanted (black arrows) to musculoskeletal tissues in need of regeneration.

Abbreviation: MSCs, mesenchymal stem cells.

to articular cartilage or more complex osteochondral lesions and even tendons or ligaments. ${ }^{18}$

Although MSCs provide an ideal source for direct regeneration of joint surfaces, a recent and increasing body of research is beginning to suggest that the primary benefit of these cells is derived from their paracrine activities. ${ }^{30}$ Regeneration of joint tissues has been documented after injection of MSCs; however, some studies have found that reconstitution of tissue is primarily from native cells and relatively few transplanted cells. ${ }^{40}$ Other studies have shown that the cell signaling milieu is altered after administration of MSCs with subsequent increase in Type II collagen production by the host. ${ }^{41}$ Together, these factors suggest that MSCs may be orchestrating the reparative response rather than directly replacing damaged areas. This is in line with the well-documented anti-inflammatory and immunomodulatory role of MSCs. ${ }^{18}$

\section{MSC derangements in OA and related conditions}

Select findings raise suspicion that systemic depletion and derangement of MSCs may contribute to OA pathophysiology. MSCs from patients with OA can be decreased in number with concomitant impairment of proliferation and differentiation capacity. ${ }^{42}$ Specifically, depressed chondrogenesis and adipogenesis with increased osteogenesis are typical in OA patients. The majority of this work has been performed in bone marrow-derived MSCs, yet similar results have been documented from a variety of tissue sources suggesting a systemic nature to the changes. ${ }^{42}$
MSC alterations seem to be involved in disease-specific pathology. Decreased chondrogenesis and increased osteogenesis in OA could be potentiating loss and/or lack of replacement of articular cartilage with subsequent production of osteophytes. Functional MSC changes have also been documented in osteoporosis and osteonecrosis. ${ }^{43-46}$ For osteonecrosis, the differentiation profile demonstrates maintained MSC chondrogenesis and adipogenesis with decreased osteogenesis, the inverse of what has been observed in OA (unpublished data). Decreased osteogenesis in osteonecrosis could represent a failure to reconstitute the failing tissue, in this case bone. Thus in both OA and osteonecrosis, a plausible explanation can be made for disease pathophysiology through correlation with specific alterations present in MSC capability. Although MSC dysfunction appears to be systemic in these degenerative musculoskeletal conditions, bone marrow may be impacted to the greatest degree. Studies from OA and osteonecrosis patients have shown the most prominent impact on bone marrow-derived MSCs, with adipose-derived MSCs maintaining a greater level of functionality. ${ }^{47}$ This observation may be secondary to the intense physiologic stress of the bone marrow microenvironment relative to comparatively quiescent adipose tissue. Differential dysfunction of MSCs by disease and tissue source has important implications for therapeutic implementation of cell transplantation therapies.

\section{Evidence from preclinical models}

Foundational work was performed by Murphy et al in a goat model of post-traumatic OA. ${ }^{40}$ They resected the anterior 
cruciate ligament and medial meniscus, leading to articular degeneration and osteophyte formation. Joints that received subsequent injection of autologous MSCs showed improvement compared with control joints via meniscal and cartilage regeneration. Interestingly, transplanted MSCs were primarily localized to synovial and meniscal surfaces, suggesting that they served an orchestrative role as opposed to supplying the direct building blocks of regeneration. Similar outcomes with injected MSCs preserving joint integrity have been demonstrated in a variety of knee OA models including horse, sheep, rat, mouse, rabbit, and guinea pig. ${ }^{41,48-53}$ Specifically in the rat model documented by Horie et al, MSCs demonstrated upregulated expression of bone morphogenetic protein 2 , parathyroid hormone-like hormone, and Indian hedgehog, which subsequently increased Type II collagen production in the native joint tissue. ${ }^{41}$ This gives further credence to the theory of MSC governance of regeneration through paracrine stimulation of the local microenvironment.

\section{Evidence from human trials}

Proof-of-concept evidence from preclinical studies has led to the genesis of multiple clinical trials. ${ }^{54}$ Much of this work remains in nascent stages; however, in 2015, clinicaltrials. gov documents 14 open clinical trials addressing OA with MSCs (Table 1). ${ }^{55-68}$ Most studies utilize autologous bone marrow- or adipose-derived MSCs. Some incorporate sameday harvesting and transplantation procedures with autologous bone marrow concentrate or stromal vascular fraction, the latter being a known source of adipose-derived MSCs. ${ }^{69}$ Others employ a two-stage process with harvesting followed by ex vivo expansion prior to transplantation. Approaches with allogenic MSC sources include umbilical cord blood or bone marrow.

Additional key differentiating factors between these ongoing studies are cell dose and vehicle of administration. The number of cells in a single dose is highly variable as indicated in Table 1. Optimal titration will likely be a finding of more advanced-phase clinical trials after initial safety and efficacy are established. Most ongoing clinical trials are delivering the MSCs through direct injection in the absence of a scaffold or matrix; nevertheless, some are using adjuvants such as hyaluronic acid. The reasons for this are primarily twofold - regulatory and philosophical. MSCs, like any cell therapy, are a complex therapeutic. Regulatory barriers to implementation of these biologics are quite stringent, which is only further complicated by multi-component interventions such as MSCs embedded in a biomatrix. Philosophical reasons for scaffold-free injection are rooted in preclinical evidence suggesting that the more powerful role of MSCs in treating $\mathrm{OA}$ rests with orchestration of regeneration as opposed to providing the direct building blocks.

\section{Modes of derivation and delivery for MSCs}

Despite preponderance of scaffold-free autologous MSCs in ongoing clinical trials, intense preclinical efforts are being directed toward optimizing derivation and delivery of MSCs. This bears further discussion as development in these areas may shift future trends. ${ }^{31}$ The first issue to consider is donor source. Proponents of autologous products value safety and predictability from the lack of immunogenicity, whereas those on the side of allogenic MSCs argue that young and healthy donors overcome issues related to MSC suppression that may have potentiated disease in the first place. ${ }^{70}$ No clear winner has been determined, yet autologous products are more common likely due to the less cumbersome regulatory issues. MSC tissue source is another area of investigation. Bone marrow, adipose, and umbilical cord blood have been used most commonly, but the wide distribution of these cells has generated interest in other locations such as synovium and periosteum. ${ }^{71,72}$ Bone marrow has been the historic leader and is the most well studied. Some authors have found a trophic advantage with bone marrow-derived MSCs; however, newer evidence stands in contrast to this dogma by suggesting that bone marrow-derived MSCs may be less potent in comparison to MSCs that reside in adipose tissue. ${ }^{19,33-35,37,38,50,73-75}$ Perhaps this is secondary to the physiologic stress and high turnover present in bone marrow compared with adipose, but the exact mechanism is yet to be elucidated.

Regardless of MSC source, physicians and scientists must determine whether single procedure cell transplantation or staged procedure cell transplantation after ex vivo expansion is more desirable. Single procedure techniques are more feasible with bone marrow and adipose. Bone marrow can be aspirated and centrifuged in the operative suite to derive a mononuclear cell concentrate prior to transplantation. ${ }^{76}$ Adipose tissue can similarly be fractionated in the operative suite to derive the stromal vascular fraction prior to transplantation. ${ }^{69}$ Both approaches allow the patient to receive complete treatment in one sitting, with delivery of MSCs admixed with other stromal and parenchymal cellular components from the native tissue bed. By contrast, ex vivo expansion allows for purification and standardization of the cell product. ${ }^{77}$ Quality control is easier to perform with this approach and an exact number of MSCs can be transplanted. However, this technique requires two procedures, and is more 


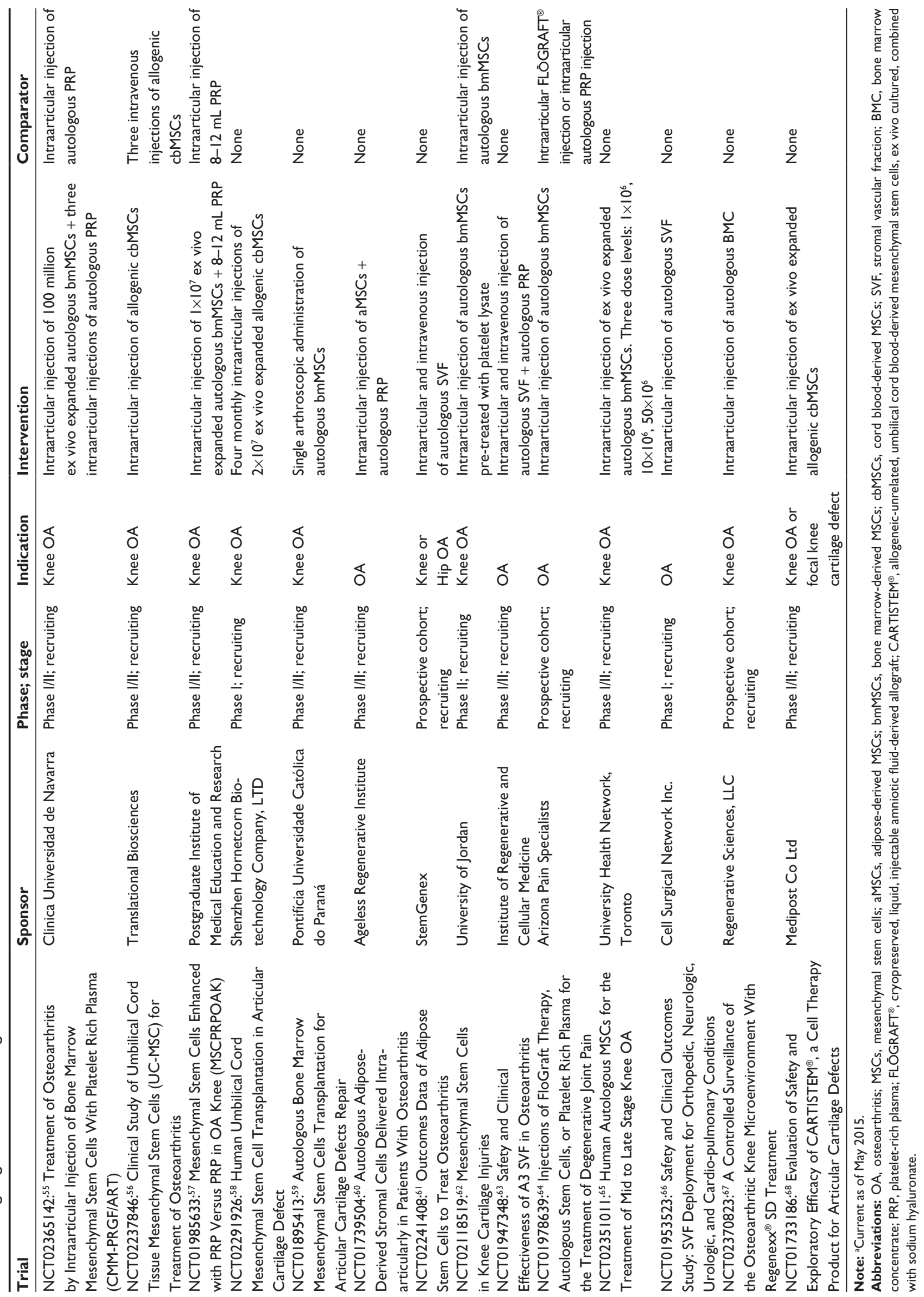


labor intensive and costly. Furthermore, it carries added concern that hyperproliferation prior to transplantation may alter cell potency and phenotype. ${ }^{78}$

Interest has also been directed toward biocompatible MSC carriers. Myriad scaffolds and biomatrices have been developed to provide a structured vehicle for delivery. ${ }^{79}$ As mentioned previously, regulatory issues have prevented co-administration with MSCs from being more common in clinical studies, but the preclinical literature is rich with biologics in development. Matrices used to date in vivo have combined hydrogels impregnated with MSCs for regeneration of osteochondral defects; however, these studies have been relatively small and have short-term follow-up. ${ }^{80,81}$ Scaffolds offer the potential to more precisely localize MSC delivery and direct their proliferation and differentiation. The ideal carrier would have a variety of properties including, but not limited to the following: biocompatibility and biodegradability timed with tissue healing, gas and nutrient permeability, porous structure to support cell migration, malleability and strength to maintain mechanical integrity in the joint, and be inductive and conductive of osteochondral tissue. ${ }^{31}$ Unfortunately, this combination has remained elusive, but options demonstrating promise include synthetic scaffolds constructed from polymers and hydrogels primarily derived from components native to the joint such as collagen, hyaluronic acid, alginate, and chitosan. ${ }^{31}$ Matrices are also being designed with impregnation of growth factors to optimize the trophic microenvironment. How these biologics are tailored for specific purposes moving forward will largely depend on whether the focus is to potentiate the ability of MSCs to orchestrate regeneration or directly differentiate and replace damaged tissue.

\section{Conclusion}

$\mathrm{OA}$ is a prevalent chronic degenerative joint disease that will continue to impose an increasing burden on the aging population unless disease-modifying therapies are developed. The current standard of care with risk factor modification, pain management, and joint replacement will be inadequate to meet the needs of society moving forward. MSCs offer a potential regenerative solution given their ability to differentiate to all tissues within a joint and modulate the local inflammatory response. Although these characteristics suggest they provide ideal building blocks to restore damaged joints, a strong body of evidence supports MSC-guided regeneration through paracrine stimulation of native tissue. Further preclinical work will be mandatory to establish the mechanism by which MSCs have demonstrated a proof-of-concept to heal OA lesions as this will have critical implications for clinical implementation strategies.

Determining the ideal MSC source, processing, and delivery vehicle are further challenges that must be addressed to optimize biologics-based treatment of OA. Bone marrow, adipose, and cord blood offer different advantages as does derivation and application in a single procedure versus staged transplantation after ex vivo expansion. Although scaffoldfree injection of MSCs predominates ongoing clinical trials, biomatrices may prove a critical adjuvant as these therapies evolve. In 2015, the translation of MSCs to clinical therapy for OA has been slow; however, signs of progress are evident and ongoing trials may show efficacy to indicate these products can serve as the disease-modifying therapy necessary to stem the tide of OA.

\section{Disclosure}

Dr Sierra is a paid consultant for Biomet (Warsaw, IN, USA). The authorship group has received research support from Biomet and an Accelerated Regenerative Medicine grant from the Mayo Clinic Center for Regenerative Medicine.

\section{References}

1. Buckwalter JA, Martin JA. Osteoarthritis. Adv Drug Deliv Rev. 2006;58(2):150-167.

2. Brooks PM. Impact of osteoarthritis on individuals and society: how much disability? Social consequences and health economic implications. Curr Opin Rheumatol. 2002;14(5):573-577.

3. Kurtz S, Ong K, Lau E, Mowat F, Halpern M. Projections of primary and revision hip and knee arthroplasty in the United States from 2005 to 2030. J Bone Joint Surg Am. 2007;89(4):780-785.

4. Kurtz SM, Lau E, Ong K, Zhao K, Kelly M, Bozic KJ. Future young patient demand for primary and revision joint replacement: national projections from 2010 to 2030. Clin Orthop Relat Res. 2009;467(10):2606-2612.

5. Hootman JM, Helmick CG. Projections of US prevalence of arthritis and associated activity limitations. Arthritis Rheum. 2006;54(1):226-229.

6. Yelin E, Murphy L, Cisternas MG, Foreman AJ, Pasta DJ, Helmick CG. Medical care expenditures and earnings losses among persons with arthritis and other rheumatic conditions in 2003, and comparisons with 1997. Arthritis Rheum. 2007;56(5):1397-1407.

7. Hochberg MC, Altman RD, April KT, et al. American College of Rheumatology 2012 recommendations for the use of nonpharmacologic and pharmacologic therapies in osteoarthritis of the hand, hip, and knee. Arthritis Care Res (Hoboken). 2012;64(4):465-474.

8. Bert JM, Gasser SI. Approach to the osteoarthritic knee in the aging athlete: debridement to osteotomy. Arthroscopy. 2002;18(9 Suppl 2): 107-110.

9. Bartlett W, Skinner JA, Gooding CR, et al. Autologous chondrocyte implantation versus matrix-induced autologous chondrocyte implantation for osteochondral defects of the knee: a prospective, randomised study. J Bone Joint Surg Br. 2005;87(5):640-645.

10. Bentley G, Biant LC, Carrington RW, et al. A prospective, randomised comparison of autologous chondrocyte implantation versus mosaicplasty for osteochondral defects in the knee. J Bone Joint Surg Br. 2003;85(2):223-230.

11. Feczko P, Hangody L, Varga J, et al. Experimental results of donor site filling for autologous osteochondral mosaicplasty. Arthroscopy. 2003; 19(7):755-761. 
12. Hangody L, Fules P. Autologous osteochondral mosaicplasty for the treatment of full-thickness defects of weight-bearing joints: ten years of experimental and clinical experience. J Bone Joint Surg Am. 2003; 85-A Suppl 2:25-32.

13. Henderson I, Francisco R, Oakes B, Cameron J. Autologous chondrocyte implantation for treatment of focal chondral defects of the knee-a clinical, arthroscopic, MRI and histologic evaluation at 2 years. Knee. 2005;12(3):209-216.

14. Knutsen G, Engebretsen L, Ludvigsen TC, et al. Autologous chondrocyte implantation compared with microfracture in the knee. A randomized trial. J Bone Joint Surg Am. 2004;86-A(3):455-464.

15. Peterson L, Minas T, Brittberg M, Lindahl A. Treatment of osteochondritis dissecans of the knee with autologous chondrocyte transplantation: results at two to ten years. J Bone Joint Surg Am. 2003;85-A(Suppl 2): $17-24$.

16. Sampson S, Botto-van Bemden A, Aufiero D. Stem cell therapies for treatment of cartilage and bone disorders: osteoarthritis, avascular necrosis, and non-union fractures. PM R. 2015;7(4 Suppl): S26-S32.

17. Kolf CM, Cho E, Tuan RS. Mesenchymal stromal cells. Biology of adult mesenchymal stem cells: regulation of niche, self-renewal and differentiation. Arthritis Res Ther. 2007;9(1):204.

18. Glenn JD, Whartenby KA. Mesenchymal stem cells: emerging mechanisms of immunomodulation and therapy. World J Stem Cells. 2014;6(5):526-539.

19. Strioga M, Viswanathan S, Darinskas A, Slaby O, Michalek J. Same or not the same? Comparison of adipose tissue-derived versus bone marrow-derived mesenchymal stem and stromal cells. Stem Cells Dev. 2012;21(14):2724-2752.

20. Ernst E. Complementary or alternative therapies for osteoarthritis. Nat Clin Pract Rheumatol. 2006;2(2):74-80.

21. Zhang W, Moskowitz RW, Nuki G, et al. OARSI recommendations for the management of hip and knee osteoarthritis, Part II: OARSI evidence-based, expert consensus guidelines. Osteoarthritis Cartilage. 2008;16(2):137-162.

22. Raynauld JP, Buckland-Wright C, Ward R, et al. Safety and efficacy of long-term intraarticular steroid injections in osteoarthritis of the knee: a randomized, double-blind, placebo-controlled trial. Arthritis Rheum. 2003;48(2):370-377.

23. Celeste C, Ionescu M, Robin Poole A, Laverty S. Repeated intraarticular injections of triamcinolone acetonide alter cartilage matrix metabolism measured by biomarkers in synovial fluid. J Orthop Res. 2005;23(3):602-610.

24. Nakazawa F, Matsuno H, Yudoh K, Watanabe Y, Katayama R, Kimura T. Corticosteroid treatment induces chondrocyte apoptosis in an experimental arthritis model and in chondrocyte cultures. Clin Exp Rheumatol. 2002;20(6):773-781.

25. Wyles CC, Houdek MT, Wyles SP, Wagner ER, Behfar A, Sierra RJ Differential cytotoxicity of corticosteroids on human mesenchymal stem cells. Clin Orthop Relat Res. 2015;473(3):1155-1164.

26. Rutjes AW, Juni P, da Costa BR, Trelle S, Nuesch E, Reichenbach S. Viscosupplementation for osteoarthritis of the knee: a systematic review and meta-analysis. Ann Intern Med. 2012;157(3):180-191.

27. Bozic KJ, Chiu VW, Slover JD, Immerman I, Kahn JG. Health state utility in patients with osteoarthritis of the hip and total hip arthroplasty. J Arthroplasty. 2011;26(6 Suppl):129-132. e121-e122.

28. Nwachukwu BU, McLawhorn AS, Simon MS, et al. Management of end-stage ankle arthritis: cost-utility analysis using direct and indirect costs. J Bone Joint Surg Am. 2015;97(14):1159-1172.

29. Pinkas D, Wiater JM, Spencer EE Jr, et al. Shoulder prosthetic arthroplasty options in 2014: what to do and when to do it. Instr Course Lect. 2015;64:193-202.

30. Barry F, Murphy M. Mesenchymal stem cells in joint disease and repair. Nat Rev Rheumatol. 2013;9(10):584-594.

31. Noth U, Steinert AF, Tuan RS. Technology insight: adult mesenchymal stem cells for osteoarthritis therapy. Nat Clin Pract Rheumatol. 2008;4(7):371-380.
32. Abu Kasim NH, Govindasamy V, Gnanasegaran N, et al. Unique molecular signatures influencing the biological function and fate of post-natal stem cells isolated from different sources. J Tissue Eng Regen Med. 2012.

33. Gimble J, Guilak F. Adipose-derived adult stem cells: isolation, characterization, and differentiation potential. Cytotherapy. 2003;5(5):362-369.

34. Im GI, Shin YW, Lee KB. Do adipose tissue-derived mesenchymal stem cells have the same osteogenic and chondrogenic potential as bone marrow-derived cells? Osteoarthritis Cartilage. 2005;13(10):845-853.

35. Liu TM, Martina M, Hutmacher DW, Hui JH, Lee EH, Lim B. Identification of common pathways mediating differentiation of bone marrow- and adipose tissue-derived human mesenchymal stem cells into three mesenchymal lineages. Stem Cells. 2007;25(3):750-760.

36. Shafiee A, Seyedjafari E, Soleimani M, Ahmadbeigi N, Dinarvand P, Ghaemi N. A comparison between osteogenic differentiation of human unrestricted somatic stem cells and mesenchymal stem cells from bone marrow and adipose tissue. Biotechnol Lett. 2011;33(6):1257-1264.

37. Stockmann P, Park J, von Wilmowsky C, et al. Guided bone regeneration in pig calvarial bone defects using autologous mesenchymal stem/ progenitor cells - a comparison of different tissue sources. J Craniomaxillofac Surg. 2012;40(4):310-320.

38. Wen Y, Jiang B, Cui J, et al. Superior osteogenic capacity of different mesenchymal stem cells for bone tissue engineering. Oral Surg Oral Med Oral Pathol Oral Radiol. 2013;116(5):e324-e332.

39. Zuk PA, Zhu M, Ashjian P, et al. Human adipose tissue is a source of multipotent stem cells. Mol Biol Cell. 2002;13(12):4279-4295.

40. Murphy JM, Fink DJ, Hunziker EB, Barry FP. Stem cell therapy in a caprine model of osteoarthritis. Arthritis Rheum. 2003;48(12):3464-3474.

41. Horie $\mathrm{M}$, Choi $\mathrm{H}$, Lee $\mathrm{RH}$, et al. Intra-articular injection of human mesenchymal stem cells (MSCs) promote rat meniscal regeneration by being activated to express Indian hedgehog that enhances expression of type II collagen. Osteoarthritis Cartilage. 2012;20(10): 1197-1207.

42. Murphy JM, Dixon K, Beck S, Fabian D, Feldman A, Barry F. Reduced chondrogenic and adipogenic activity of mesenchymal stem cells from patients with advanced osteoarthritis. Arthritis Rheum. 2002;46(3):704-713.

43. Giannoudis P, Tzioupis C, Almalki T, Buckley R. Fracture healing in osteoporotic fractures: is it really different? A basic science perspective. Injury. 2007;38(Suppl 1):S90-S99.

44. Hernigou P, Beaujean F. Abnormalities in the bone marrow of the iliac crest in patients who have osteonecrosis secondary to corticosteroid therapy or alcohol abuse. J Bone Joint Surg Am. 1997;79(7): 1047-1053.

45. Lee JS, Roh HL, Kim CH, Jung JS, Suh KT. Alterations in the differentiation ability of mesenchymal stem cells in patients with nontraumatic osteonecrosis of the femoral head: comparative analysis according to the risk factor. J Orthop Res. 2006;24(4):604-609.

46. Moerman EJ, Teng K, Lipschitz DA, Lecka-Czernik B. Aging activates adipogenic and suppresses osteogenic programs in mesenchymal marrow stroma/stem cells: the role of PPAR-gamma2 transcription factor and TGF-beta/BMP signaling pathways. Aging Cell. 2004;3(6): 379-389.

47. Wyles CC, Houdek MT, Crespo-Diaz RJ, et al. Adipose-derived mesenchymal stem cells are phenotypically superior for regeneration in the setting of osteonecrosis of the femoral head. Clin Orthop Relat Res. 2015.

48. Al Faqeh H, Nor Hamdan BM, Chen HC, Aminuddin BS, Ruszymah BH. The potential of intra-articular injection of chondrogenic-induced bone marrow stem cells to retard the progression of osteoarthritis in a sheep model. Exp Gerontol. 012;47(6):458-464.

49. Diekman BO, Wu CL, Louer CR, et al. Intra-articular delivery of purified mesenchymal stem cells from C57BL/6 or MRL/MpJ superhealer mice prevents posttraumatic arthritis. Cell Transplant. 2013;22(8):1395-1408.

50. Frisbie DD, Kisiday JD, Kawcak CE, Werpy NM, McIlwraith CW. Evaluation of adipose-derived stromal vascular fraction or bone marrow-derived mesenchymal stem cells for treatment of osteoarthritis. J Orthop Res. 2009;27(12):1675-1680. 
51. Guercio A, Di Marco P, Casella S, et al. Production of canine mesenchymal stem cells from adipose tissue and their application in dogs with chronic osteoarthritis of the humeroradial joints. Cell Biol Int. 2012; 36(2):189-194.

52. Sato M, Uchida K, Nakajima H, et al. Direct transplantation of mesenchymal stem cells into the knee joints of Hartley strain guinea pigs with spontaneous osteoarthritis. Arthritis Res Ther. 2012;14(1):R31.

53. Toghraie F, Razmkhah M, Gholipour MA, et al. Scaffold-free adiposederived stem cells (ASCs) improve experimentally induced osteoarthritis in rabbits. Arch Iran Med. 2012;15(8):495-499.

54. Xia P, Wang X, Lin Q, Li X. Efficacy of mesenchymal stem cells injection for the management of knee osteoarthritis: a systematic review and meta-analysis. Int Orthop. Epub 2015 May 6.

55. US National Library of Medicine. clinicaltrials.gov. Available from: https:/clinicaltrials.gov/ct2/show/NCT02365142. NLM identifier: NCT02365142. Accessed 2015.

56. US National Library of Medicine. clinicaltrials.gov. Available from: https:/clinicaltrials.gov/ct2/show/NCT02237846. NLM identifier: NCT02237846. Accessed 2015.

57. US National Library of Medicine. clinicaltrials.gov. Available from: https:/clinicaltrials.gov/ct2/show/NCT01985633. NLM identifier: NCT01985633. Accessed 2015.

58. US National Library of Medicine. clinicaltrials.gov. Available from: https:/clinicaltrials.gov/ct2/show/NCT02291926. NLM identifier: NCT02291926. Accessed 2015.

59. US National Library of Medicine. clinicaltrials.gov. Available from: https:/clinicaltrials.gov/ct2/show/NCT01895413. NLM identifier: NCT01895413. Accessed 2015

60. US National Library of Medicine. clinicaltrials.gov. Available from: https:/clinicaltrials.gov/ct2/show/NCT01739504. NLM identifier: NCT01739504. Accessed 2015.

61. US National Library of Medicine. clinicaltrials.gov. Available from: https://clinicaltrials.gov/ct2/show/NCT02241408. NLM identifier: NCT02241408. Accessed 2015.

62. US National Library of Medicine. clinicaltrials.gov. Available from: https:/clinicaltrials.gov/ct2/show/NCT02118519. NLM identifier: NCT02118519. Accessed 2015.

63. US National Library of Medicine. clinicaltrials.gov. Available from: https:/clinicaltrials.gov/ct2/show/NCT01947348. NLM identifier: NCT01947348. Accessed 2015.

64. US National Library of Medicine. clinicaltrials.gov. Available from: https:/clinicaltrials.gov/ct2/show/NCT01978639. NLM identifier: NCT01978639. Accessed 2015.

65. US National Library of Medicine. clinicaltrials.gov. Available from: https:/clinicaltrials.gov/ct2/show/NCT02351011. NLM identifier: NCT02351011. Accessed 2015.

66. US National Library of Medicine. clinicaltrials.gov. Available from: https://clinicaltrials.gov/ct2/show/NCT01953523. NLM identifier: NCT01953523. Accessed 2015.
67. US National Library of Medicine. clinicaltrials.gov. Available from: https:/clinicaltrials.gov/ct2/show/NCT02370823. NLM identifier: NCT02370823. Accessed 2015.

68. US National Library of Medicine. clinicaltrials.gov. Available from: https:/clinicaltrials.gov/ct2/show/NCT01733186. NLM identifier: NCT01733186. Accessed 2015.

69. Michalek J, Moster R, Lukac L, et al. Autologous adipose tissue-derived stromal vascular fraction cells application in patients with osteoarthritis. Cell Transplant. Epub 2015 Jan 20.

70. Kristjansson B, Honsawek S. Current perspectives in mesenchymal stem cell therapies for osteoarthritis. Stem Cells Int. 2014;2014:194318.

71. Chang H, Docheva D, Knothe UR, Knothe Tate ML. Arthritic periosteal tissue from joint replacement surgery: a novel, autologous source of stem cells. Stem Cells Transl Med. 2014;3(3):308-317.

72. Koga H, Muneta T, Ju YJ, et al. Synovial stem cells are regionally specified according to local microenvironments after implantation for cartilage regeneration. Stem Cells. 2007;25(3):689-696.

73. Liao HT, Chen CT. Osteogenic potential: Comparison between bone marrow and adipose-derived mesenchymal stem cells. World J Stem Cells. 2014;6(3):288-295.

74. Niemeyer P, Fechner K, Milz S, et al. Comparison of mesenchymal stem cells from bone marrow and adipose tissue for bone regeneration in a critical size defect of the sheep tibia and the influence of platelet-rich plasma. Biomaterials. 2010;31(13):3572-3579.

75. Vishnubalaji R, Al-Nbaheen M, Kadalmani B, Aldahmash A, Ramesh T. Comparative investigation of the differentiation capability of bonemarrow- and adipose-derived mesenchymal stem cells by qualitative and quantitative analysis. Cell Tissue Res. 2012;347(2):419-427.

76. Houdek MT, Wyles CC, Martin JR, Sierra RJ. Stem cell treatment for avascular necrosis of the femoral head: current perspectives. Stem Cells Cloning. 2014;7:65-70.

77. Torre ML, Lucarelli E, Guidi S, et al. Ex vivo expanded mesenchymal stromal cell minimal quality requirements for clinical application. Stem Cells Dev. 15 2015;24(6):677-685.

78. Bentivegna A, Miloso M, Riva G, et al. DNA Methylation changes during in vitro propagation of human mesenchymal stem cells: implications for their genomic stability? Stem Cells Int. 2013;2013:192425.

79. Bornes TD, Adesida AB, Jomha NM. Mesenchymal stem cells in the treatment of traumatic articular cartilage defects: a comprehensive review. Arthritis Res Ther. 2014;16(5):432.

80. Giannini S, Buda R, Battaglia M, et al. One-step repair in talar osteochondral lesions: 4-year clinical results and t2-mapping capability in outcome prediction. Am J Sports Med. 2013;41(3):511-518.

81. Gobbi A, Chaurasia S, Karnatzikos G, Nakamura N. Matrix-induced autologous chondrocyte implantation versus multipotent stem cells for the treatment of large patellofemoral chondral lesions: a nonrandomized prospective trial. Cartilage. 2015;6(2):82-97.
Stem Cells and Cloning: Advances and Applications

\section{Publish your work in this journal}

Stem Cells and Cloning: Advances and Applications is an international, peer-reviewed, open access journal. Areas of interest in stem cell research include: Embryonic stem cells; Adult stem cells; Blastocysts; Cordblood stem cells; Stem cell transformation and culture; Therapeutic cloning; Umbilical cord blood and bone marrow cells; Laboratory,

\section{Dovepress}

animal and human therapeutic studies; Philosophical and ethical issues related to stem cell research. This journal is indexed on CAS. The manuscript management system is completely online and includes a quick and fair peer-review system. Visit http://www.dovepress.com/ testimonials.php to read real quotes from published authors. 